\title{
Designing organizational structures of production systems using a process-oriented approach
}

\author{
Gert Zülch and Bernd Brinkmeier \\ ifab - Institute of Human and Industrial Engineering \\ University of Karlsruhe \\ Kaiserstrasse 12, D-76128 Karlsruhe, Germany \\ Tel. +49-721-608-4250 Fax. +49-721-694557 \\ E-mail:bernd.brinkmeier@mach.uni-karlsruhe.de
}

\begin{abstract}
This paper discusses a process-oriented approach for designing organizational structures of production systems. Based on a suitable characterization of order related processes on one hand, and the personnel on the other hand, organizational structures with a high performance can be defined. The concept of shaping process-oriented organizational structures is connected to a simulation-aided approach in order to evaluate the dynamic behavior of planned production systems and to perform the planning procedure in a flexible and efficient way. The dynamic analyses are carried out using the simulation tool FEMOS.
\end{abstract}

\section{Keywords}

Production Management, Process Orientation, Organizational Structures, Continuous Reorganization, Modeling, Simulation.

\section{INTRODUCTION}

Currently, radical changes are occuring in many companies in order to fulfill the trend of increasing demands on three typical company goals, namely cost, quality and time. Furthermore the acceleration of change of factors that influence the company is dramatically increasing the complexity. Still prevailing orientation and

Advances in Production Management Systems N. Okino, H. Tamura \& S. Fujii (Eds.)

(C) 1998 IFIP. Published by Chapman \& Hall 
formation of the activities along a rigid company departmental structure are dropped in favor of an alignment towards processes (Figure 1). While doing so, the processes are regarded beyond their limitations of cost centers and departments under the aspect of the maximum customer benefit and the concentration towards the value added chain (cf. Hanewickel 1994).

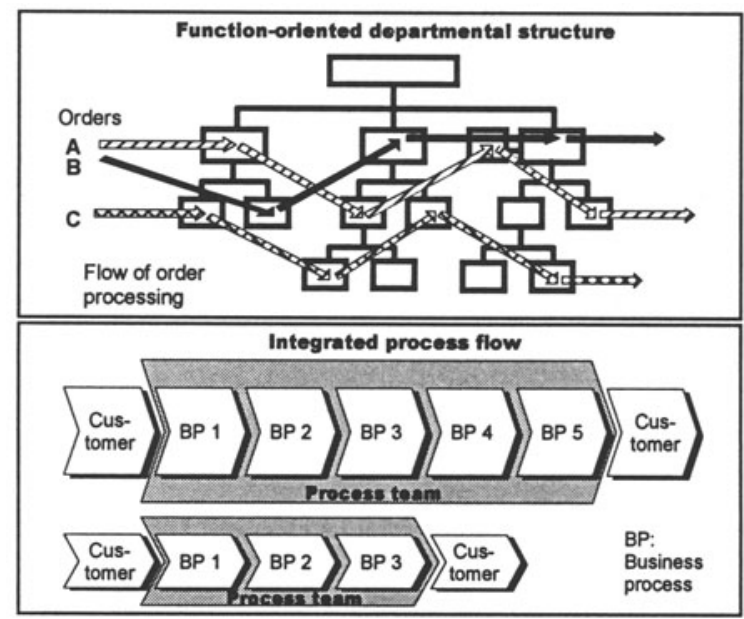

Figure 1 Comparison of order processing in function- and process-oriented organizational structures.

In order to increase enterprise performance, especially flow increasing organizational concepts are discussed. Redesign of departmental structures should include all sections of the order processing, not only in production, but also in preproductive sectors like sales, design and operations planning (Erbacher 1993).

Most of the organizational forms that exist in theory and practice aim towards the features function and object, through which both organizational basic forms are determined. This is, on one hand, the functional organization where departmental structures are only directed through functions, and on the other hand, the divisional organization in which tasks are arranged according to objects, i.e. the products or services that are produced by the enterprise. Most of the other organizational forms are between these both extreme basic forms, which can be derived through variation and/or a combination of the functional and the divisional organization (Gerlach 1983).

From an organizational point of view, new shaping possibilities are opened through process-oriented business modeling (Krcmar and Schwarzer 1994). The high complexity of these modeling and designing methods force the need for making tools available to support the problem solution.

In the context of this paper, a methodological base for planning of processoriented organizational structures is presented. The method concentrates on the pre-productive areas in industrial companies. A general structuring offers starting 
points for realization of flow forcing forms, because a company organization along the processing direction of the order is made possible. The developed concept will be used afterwards on a specific company model as an example.

\section{METHODOLOGY}

With the developed concept, a method for the shaping of process-oriented organizational structures will be made available. Based on the knowledge of business processes and their networks, a concept for the design of organizational structures will be created. The procedure supports the realization of different company specific goals.

\subsection{Overview of process-oriented structuring}

Process-oriented structures can be realized in the following steps:

- Selection: Definition of the problem and selection of necessary processes, determination of main emphasis of organizational redesign.

- Process analysis: Modeling of process networks.

- Quantification: Completion of processes with operation times and order quantities.

- Conception: Shaping of organizational structures according to different structuring strategies, modeling and simulation, evaluation and interpretation of results, proposition of organizational changes.

- Realization: Support of introduction of organizational measures.

In the initial step, planning constraints should be defined. It has to be settled which processes are included in the investigation and which products should be taken into consideration. Additionally, the order spectrum for creating a new organizational structure must be considered. After defining these constraints, the process analysis takes place. Doing this, the logical flow of the processes must be determined and modeled in form of process networks. During modeling, characterization of processes can be realized by assigning attributes to the processes in question. In the third step, operation times are determined and the process model is connected with the order spectrum. With this quantification, the capacity requirements of the observed period can be taken into consideration.

Based on the characterization of network processes and the personnel abilities, process-oriented forms of organizational structures like flow-oriented creation of teams. may be defined. According to the high level of decomposition, it is possible to come to a more differentiated organizational structure than from a functional point of view. The fifth step covers installing the planned organizational structure into the company. 
The most important steps of the method and the structuring strategies are deepend below.

\subsection{Modeling of process networks}

Starting point for modeling process-oriented organizational structures is the modeling of business processes (or activities at the most detailed level) of the order processing.

The modeling of process networks is supported by an object-oriented modeling technique and a special process library which has been developed by the ifabinstitute of the University of Karlsruhe (Zülch and Fischer 1995). The library consists of detailed process network elements for the technical processing of customer orders and is working as a reference model (especially in one-of-a-kind and small series production in machine industry). The emphasis is laid upon the pre-productive sectors such as sales, design and operations planning.

During modeling, processes out of the library are characterized by their general requirements on personnel abilities or technical resources (Figure 2). The definition of the process requirements is supported by a special characterization in form of a morphological scheme (Figure 3). The basic set of attributes in the scheme can be further detailed under company specific constraints.

After the flow of processes is determined, processes are completed by information about operation times, related orders and the order's customer.

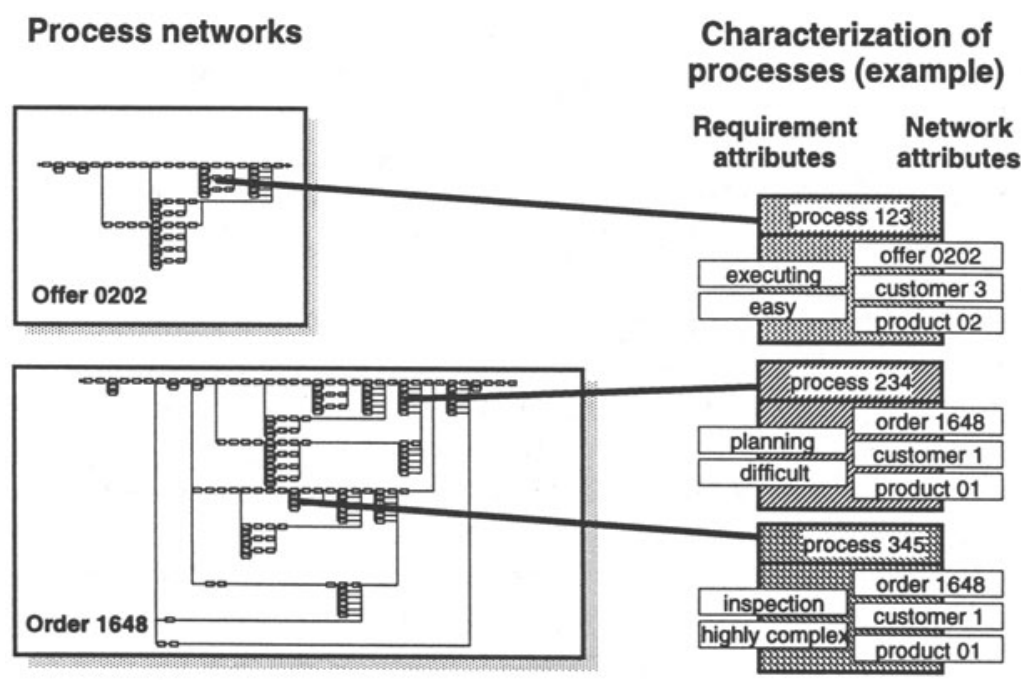

Figure 2 Modeling of processes and process networks. 


\begin{tabular}{|c|c|c|c|c|c|c|}
\hline \multicolumn{2}{|r|}{$\begin{array}{l}\text { Process type } \\
\text { feature }\end{array}$} & \multicolumn{5}{|c|}{ Feature characteristics } \\
\hline 1 & $\begin{array}{l}\text { OBJECT } \\
\text { REFERENCES }\end{array}$ & Order & \multicolumn{2}{|c|}{ Offer } & & Internal \\
\hline 2 & $\begin{array}{c}\text { SUBJECT } \\
\text { REFERENCES }\end{array}$ & \multicolumn{2}{|c|}{$\begin{array}{l}\text { Customer } \\
\text { reference }\end{array}$} & \multicolumn{3}{|c|}{$\begin{array}{l}\text { Neutral to } \\
\text { the customer }\end{array}$} \\
\hline 3 & $\begin{array}{l}\text { TYPE OF } \\
\text { TASKS }\end{array}$ & Planning & Directing & \multicolumn{2}{|c|}{ Executing } & Inspection \\
\hline 4 & $\begin{array}{l}\text { PROFILE OF } \\
\text { TASKS }\end{array}$ & $\begin{array}{l}\text { Simple type } \\
\text { of task }\end{array}$ & $\begin{array}{l}\text { Difficult type } \\
\text { of task }\end{array}$ & \multicolumn{2}{|c|}{$\begin{array}{c}\text { Complex type } \\
\text { of task }\end{array}$} & $\begin{array}{l}\text { Highly complex } \\
\text { type of task }\end{array}$ \\
\hline 5 & $\begin{array}{l}\text { PROCESSING } \\
\text { TIMES }\end{array}$ & Short & \multicolumn{2}{|c|}{ Medium } & & Long \\
\hline 6 & $\begin{array}{l}\text { TYPE OF } \\
\text { ORDERS }\end{array}$ & $\begin{array}{l}\text { New } \\
\text { order }\end{array}$ & \multicolumn{2}{|c|}{$\begin{array}{c}\text { Variant } \\
\text { order }\end{array}$} & & $\begin{array}{l}\text { Repeat } \\
\text { order }\end{array}$ \\
\hline 7 & $\begin{array}{l}\text { PRODUCT } \\
\text { STRUCTURES }\end{array}$ & $\begin{array}{l}\text { Few parts } \\
\text { product }\end{array}$ & \multicolumn{2}{|c|}{$\begin{array}{c}\text { Multiple component } \\
\text { product with a } \\
\text { simple structure }\end{array}$} & & $\begin{array}{l}\text { tiple component } \\
\text { roduct with a } \\
\text { mplex structure }\end{array}$ \\
\hline
\end{tabular}

Figure 3 Characterization of processes.

\subsection{Conception phase}

Within the conception phase development and modeling of organizational structures, especially job definition, takes place. This task can be proceeded according to different structuring strategies when using the process characterization for the design of organizational structures (Figure 4). The realization of strategies is tested for the company model, and eventually rejected or further pursued. While doing this, recursion steps are attached, which either behold a new model creation or represent a refinement of the existing model. In order to follow mixed structuring strategies, the succeeded use of different strategies during the recursion steps is possible; e.g. by using a task-oriented structuring strategy after structuring the system into order segments.

The determination of organizational units is the second step after job definition. With the elimination of existing departmental structures, the advantages of functional integration can be exploited throughout the whole company, if attention is laid on the complete process chain. New forms of work organization like teamoriented structures may be designed. The results are changed work contents, processes, and management structures (according to Keller 1993).

After processing of all the necessary recursion steps a new organizational form is found. This solution is checked with the help of a simulation tool. The evaluation of the simulation model is the last step of the conception phase. Measures can be analyzed and determined regarding the simulation results, which then go into the realization phase. 


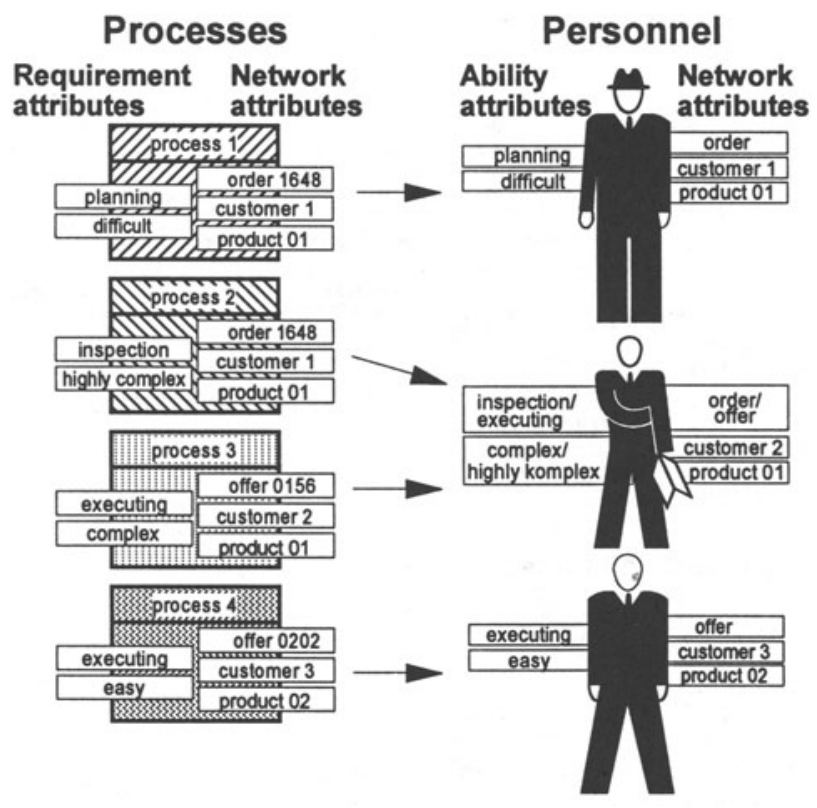

Figure 4 Allocation of processes to persons.

\subsection{Strategies of organizational design}

The following structuring strategies are regarded from the process-oriented point of view. Process-orientation in general is understood as the alignment of forms to typical customer orders and therefore, along the process chain. The term processorientation must be further broadened for the use of this concept. The developed procedures are based on characteristic information of the processes. The processorientation is focused on the process as a basic element for different structuring strategies. The process attributes are consulted as structuring criteria for the use of the strategies. For example, if customer-orientation for organization is to be preferred, personnel must be assigned to certain customers or customer groups. This assignment occurs through characteristic attributes, for example customer 1 for the attribute subject. Through attribute assignment it can be achieved that this personnel type is only qualified for processes that are initiated by customer 1 . The different structuring strategies are presented below.

\section{Customer-oriented structuring strategy}

In customer-orientation, the organization is aligned towards the production of a product according to the customer's demand. Such a customer-oriented form of organization has in general departmental structures consequently moved towards the process of offer and order completion. 


\section{Order-oriented structuring strategy}

In customer order related one-of-a-kind and small series production, orders are seen as complex, dynamic process networks. This complexity of the process network must be considered while designing departmental structures. A comprehensive knowledge of the process networks describing the order processing is a prevailing requirement for this kind of approach. Similar process networks can be combined to classes based on this approach (cf. Scheer 1994). The distinction between new, varied and repeated order, for example, may be chosen as a taxonomy criteria for different order types and thus for the departmental structure.

\section{Process-oriented structuring strategy}

The process-oriented strategy has the goal of optimizing processes along the order flow (Eversheim et al. 1993). Basis for this optimization is the identification of processes and knowledge of the relations between processes. Logical relations are represented in process networks. Structuring takes place along the production flow. Various processes are combined and assigned to personnel types. Therefore, the structuring criteria refers to single process networks that each represent an offer or an order. With this alignment of personnel types towards the process flow, departmental boundaries within order processing can be evaded, and synergy and training effects could be used efficiently.

\section{Task-oriented structuring strategy}

With this strategy, the company organization aims at repartitioning similar tasks. This is done from the point of view, that through combination of similar tasks technical competence and human related productivity are increased (Kottkamp 1993). The repetition of identical tasks leads to certain practices which reflect themselves in the reduction of processing times. The structuring concentrates in this concept on the combination of task type and task profile. The personnel is assigned to the processes according to its ability profiles.

\section{Product-oriented structuring strategies}

With product-orientation, a personnel assignment to the different products of a company is to be reached in order to achieve synergy and training effects. These effects result from the increase in technical competence and the reduced time of set up, as well as from a training degree origin from repeated execution of the same task. This is why product-oriented structuring aligns according to the requirements of products or product groups.

\section{Further structuring strategy}

The presented structuring strategies aim mainly towards the flow forcing forms of organizational design. Deviating from these bases, various strategies for creating an organization are conceivable. One goal could be, for example, the retention of a 
central purchase department. In this case, further procedure of structuring must be aligned according to this restriction. Combined forms of strategies are also conceivable. It can be advanced by the structuring in several steps, using various strategies.

The use of strategies does not have to be a single event that ends with design of a model. On the contrary, it is a continuing process, where achieved results are constantly reviewed and made subject to a permanent control of objectives (cf. Eversheim et al. 1993). The developed organizational form should be dynamically checked and verified over and over again. Moreover, the organization must be constantly adapted to the changing order structure. This dynamism is the special advantage compared to rigid, functional structures. This is the reason why it is necessary to plan the dynamism of the process flow (Kottkamp 1993).

\section{ANALYSIS OF ORGANIZATIONAL STRUCTURES WITH THE SIMULATION TOOL FEMOS}

The determination of possible effects on productivity of projected changes in the organization plays a decisive role. In a simulation model, a solution can be evaluated quickly and easily according to its quantitative effects on dynamic system behavior. For this reason, simulation programs are already widely used for the planning of production systems; but in most cases only for solving problems related to the optimization of equipment and material flow. A special type of simulation program must be used in order to analyze organizational problems. For this purpose, satisfactory modeling should take into consideration the connection between processes, personnel, and organizational units.

The simulation tool FEMOS (Fertigungs- und Montage-Simulator), has been developed by the ifab-Institute at the University of Karlsruhe since 1988. It is usually applied to research and industrial projects. The open concept allows to use this tool for a wide range of applications. Besides production organization, the study of order processing through complete production systems, from order arrival to delivery may be treated (cf. e.g. Zülch, Grobel 1992), and questions about the suitability of production system control strategies can be evaluated (cf. e.g. Zülch, Grobel 1993).

FEMOS consists of three modules: a module for modeling the production system, a simulation module with several possibilities of on-line animation, and an evaluation module for calculating logistical and economical key data such as lead time degree, utilization, work in progress and activity costs. The basic structure of this simulation tool is a general description of a production system with required elements and relations. All processes within a production system are usually deposed in process networks. During the simulation, the processing of orders, represented by networks, is performed by personnel of interlocked organizational units. A production system is modeled by the following basic elements (cf. Zülch, Brinkmeier 1995): persons with abilities to perform a set of processes or activities 
and competences for a set of work places; working hours; work places with feasibility for a set of processes; material and inventory; processes with manual and machine operation times; process networks, and orders with due dates.

FEMOS regards the order processing within a production system as a flow of orders, that consist of different process networks. These networks may be modeled graphically, thus defining sequences and parallel activities.

The simulation itself is mimicking processing, initiated by the arriving orders. This is dominated by competition of orders on limited production resources. Every activity of an order demands resources, such as work places and/or persons, which are able to fulfill this specific activity. These relations are the aspects of the organizational structure of a production system. During the simulation run certain event flows can be animated, such as Gantt-charts of order arrival, waiting queues in front of a work place or throughput-diagrams (cf. Wiendahl, Gläßner 1993), showing work contents of incoming and processed orders.

The dynamic performance of the system is influenced by the form of the organizational structure. The experience of various simulation studies shows, that the dynamic analysis of a planned production system with a simulation tool is an appropriate measure to investigate dynamic characteristics of planning solutions. benefits and shortcomings can be detected and quantified before realization of organizational changes.

\section{CASE STUDY}

The concept of shaping production management in a process-oriented way has been designed and tested with the help of a representative example, located in the area of mechanical engineering. Supported by the simulation tool FEMOS it is shown that the definition of process-oriented organizational structures is useful to increase the performance of this production system.

In this case study, a manufacturer of gear components is investigated and the focus is put on pre-productive sections of the company, such as the sales, design, and operations planning departments. The initial situation can be described as a traditionally organized company with a function-oriented departmental structure. The orders are processed in the sales department with 13 employees, the design department with 20 employees, the operations planning department with 6 employees and the calculation department with 3 employees. The load of the 42 employees is composed of an average annual quantity of 1360 offers and orders.

The result of the process analysis revealed 1628 processes. These processes must be allocated to persons during implementation of the organizational structure. About 82000 activities have to be performed by employees during the investigation period. In accordance to the work load, 1360 process networks had to be modeled. Because of the amount of data and the high number of possibilities for allocating personnel to these processes, this procedure demands computer assistance. This is why modeling is performed using the modeling module of FEMOS. 
Different strategies and goals have been tried during the development of several organizational structures. Supported by the methodology described above, the following variations have been designed and simulated:

- Variant 1 is based on a process-oriented structuring strategy. The jobs are created according to the predecessor-successor-relations within the process networks of customer orders and allocated to one of three different departments, considering the work-flow through the pre-production sections. No distinction concerning order processing is made between different customer orders.

- Variant 2 is a combination of process- and order-oriented structuring strategies. The jobs are created in the same way as in variant 1 but no organizational aggregation of jobs to departments are planned. Instead, the spectrum of customer orders is divided into three different classes according to the complexity of their process networks and are allocated to a specific segment.

- Variant 3 again is a combination of process- and order-oriented structuring strategies. In addition to the order-oriented segments of variant 2 there are two central departments assumed. The created jobs and the classes of customer orders are the same as in variant 2, but not all processes of an order are allocated to the modeled segments. Processes for contacting new customers are allocated to the first central department, and all processes after confirming an offer are allocated to the second one.

- Variant 4 follows a task-oriented structuring strategy. The jobs are created according to the process attribute profile of task. As result of the combination of tasks with the same profile (simple, difficult, complex, and highly complex), four different types of jobs can be identified which are allocated to three different departments. In contrast to variant 1 , the departments are designed without considering the work-flow. The job types, which are based on simple or difficult tasks, are allocated to two separate departments and the remaining jobs for complex and highly complex tasks to the third one.

- Variant 5 is a combination of task- and order-oriented structuring strategies. The jobs are created in the same way as in variant 4 but no organizational aggregation of jobs into departments are planned. The customer orders are divided into the same classes as in variant 2 , so again three different segments may be distinguished.

These variants are modeled with the simulation tool FEMOS and examined with regard to their dynamic behavior. The results of the simulation runs are presented in Figure 5. The evaluation is demonstrated in comparison to the initial situation. It can be seen that different strategies lead to widely different results. For example, the combination of process- and order-oriented structuring strategies of variant 2 show a good lead time. Instead of this, variant 4 follows a task-oriented structuring strategy which has bad lead times but a high reduction of personnel costs. From the results of variant 1 it can be seen that a process-oriented structuring strategy could be a good compromise in order to install a new organizational structure. 


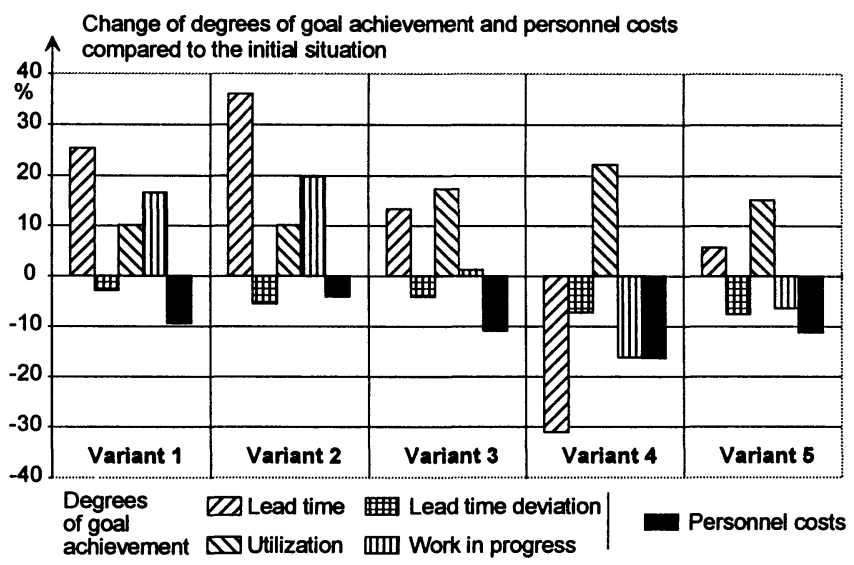

Figure 5 Results of the simulation study.

With the help of this case study it can be demonstrated, that the methodology based on a characterization of processes is suitable for designing various organizational structures. In order to support modeling and to increase acceptance of the methodology, the next step in the development is the realization of further computer support. For example, the shaping process can be improved by interactive allocation of processes to personnel, based on a graphical modeling technique. Another step in the development of the methodology should be the realization modeling decision structures in order to investigate self-controlled structures, but then an extension of the simulation tool used here becomes necessary.

\section{REFERENCES}

Gerlach, J. (1983), Entwicklung von Gestaltungsrichtlinien für eine zentrale Auftragsabwicklung in Produktionsunternehmen. Diss., TH Aachen.

Erbacher, K.-H. (1993), Neue Strukturen im Produktionsbereich. Fortschrittliche Betriebsführung und Industrial Engineering, Darmstadt, 1(42), pp. 4-7.

Eversheim, W., Krumm, S. and Heuser, T. (1993), Prozeßorientierte Auftragsabwicklung. VDI-Zeitschrift, Düsseldorf, 10(135), pp. 48-51.

Hanewickel, F. (1994), Entwicklung einer Methode zur Bewertung von Geschäftsprozessen. VDI-Verlag, Düsseldorf.

Keller, G. (1993), Informationsmanagement in objektorientierten Organisationsstrukturen. Gabler, Wiesbaden.

Kottkamp, E. (1993), Durch strukturierte Vernetzung zu größtmöglicher Kundenorientierung. Kompetenz, Frankfurt/M., 21, pp. 4-10.

Krcmar, H. and Schwarzer, B. (1994), Prozeßorientierte Unternehmensmodellierung, in Prozeßorientierte Unternehmensmodellierung, (ed. Scheer, A.-W.), Gabler, Wiesbaden, pp. 13-34. 
Scheer, A.-W. (1994), Editorial, in Prozeßorientierte Unternehmensmodellierung, (ed. Scheer, A.-W.), Gabler, Wiesbaden, pp. 1-4.

Wiendahl, H.-P. and Gläßner, J. (1993), A Monitoring System for Decision Support in Procurement and Materials Management, in Advances in Production Management Systems, (eds. Pappas, I. A. and Tatsiopoulos, I. P.), NorthHolland, Amsterdam, pp. 107-116.

Zülch, G. and Brinkmeier, B. (1995), Simulation Aided Planning of Work Structures, in Simulation Games and Learning in Production Management, (ed. J. O. Riis), Chapman \& Hall, London, pp. 91-104.

Zülch, G. and Brinkmeier, B. (1996), Simulation of Activity Costs for the Reengineering of Production Systems, in Ninth International Working Seminar on Production Economics, Igls, Pre-prints, Vol. 3, pp. 229-245.

Zülch, G. and Fischer, A. R. (1995), Library Based Modeling of Process Chains, in Re-engineering the Enterprise, (eds. Browne, J. and O'Sullivan, D.), Chapman \& Hall, London, pp. 121-130.

Zülch G. and Grobel, T. (1992), Simulating the Departmental Organization for Production to Order, in 'One-of-a-kind' Production: New Approaches, (eds. Hirsch, B. E. and Thoben, K.-D.), North-Holland, Amsterdam, pp. 177-193.

Zülch, G. and Grobel, T. (1993), Suitability of Selected Strategies of Production Control, in Advances in Production Management Systems, (eds. Pappas, I. A. and Tatsiopoulos, I. P.), North-Holland, Amsterdam, pp. 313-321.

\section{BIOGRAPHY}

Gert Zülch, born in 1946, studied Mechanical Engineering at the Technical University of Brunswick, Germany, and Industrial Engineering at the University of Technology at Aix-la-Chapelle, Germany. After his graduation as a doctor in 1979 and 10 years of experience in research and industry, in 1985 he became head of the newly founded ifab-Institute of Human and Industrial Engineering at the University of Karlsruhe, Germany.

Bernd Brinkmeier studied Mechanical Engineering from 1985 to 1989 at the University of Kaiserslautern and from 1989 to 1992 at the University of Karlsruhe. He graduated as Dipl.-Ing. in 1992 and is working as research assistant at the ifab Institute of Human and Industrial Engineering at the University of Karlsruhe, with focus on simulation aided planning of organizational structures of production systems, as well as the development and use of simulation aided seminars for continuing and vocational training in the frame of international projects of the European Community. 